\title{
Working together to improve the evidence base: abridged Cochrane reviews in Sexually Transmitted Infections
}

\author{
Nicola Low
}

The systematic review by Savaris and colleagues $^{1}$ is important for two reasons. First is the review of the treatment of pelvic inflammatory disease (PID), a common condition for which the management is contentious, driven by traditions and not necessarily evidence-based. Second, the publication of this abridged review will help to strengthen links between the Sexually Transmitted Infections Cochrane Review Group (STICRG, https://sti.cochrane.org//) ${ }^{2}$ and the journal to bring important clinical evidence from the Cochrane Library closer to our readers and other practitioners.

The systematic review of antibiotic therapy for PID, which included 37 randomised controlled trials, makes for interesting reading, particularly about the use of nitroimidazoles. ${ }^{1}$ The evidence suggests that the addition of metronidazole to any of the evaluated regimens does not improve clinical cure for either mild to moderate PID (5 trials, 1383 women) or severe PID (11 trials, 2427 women). ${ }^{1}$ The authors judged the quality of the evidence as moderate rather than high, presumably because of missing information from the trial reports (figures 1 and 2 in the published paper). ${ }^{1}$ The authors suggest that other antibiotics in the regimens tested must have provided enough anaerobic cover. Metronidazole is widely recommended to treat vaginal anaerobic bacteria that are often found in women with PID, but whose role in the upper genital tract infection is still not proven. ${ }^{3}$ Regimens that do not contain metronidazole could improve adherence to antibiotic regimens and reduce concern about antimicrobial resistance, given that nitroimidazoles are the only class of drug recommended for treatment of Trichomonas vaginalis. Clinical guideline developers should take these findings into consideration. But a quick look at the $2018 \mathrm{BASHH}$ and HIV guideline for the management of PID shows that the

Correspondence to Professor Nicola Low, Institute of Social and Preventive Medicine, University of Bern, Bern CH-3012, Switzerland; nicola.low@ispm.unibe.ch review evidence has not filtered through. The guideline gives the highest (grade 1A) recommendation for outpatient and inpatient regimens containing metronidazole. ${ }^{4}$ The search for the systematic review ended in July 2016, so new trials with improved reporting of results might provide more certainty when the authors update the Cochrane review in 2020.

The Cochrane Collaboration benefits from the copublication of systematic reviews in journals like ours because the abridged version reaches a wider audience that includes the end users. Cochrane Collaboration systematic reviews must adhere to high standards of completeness, methods to reduce the risk of bias, transparency and reporting. These requirements can make the full review very long and difficult to understand for people who are not familiar with their structure and language. An abridged review can highlight the most salient findings from a review and put them into context for a specific audience. The full Cochrane Library review provides all the details, although access is restricted to those with subscriptions or exemptions. Guideline development groups should identify and make use of the full Cochrane review, but an abridged version can also draw attention to topics that are of current relevance to clinical practice.

Sexually Transmitted Infections will consider future copublication of reviews from the STICRG and other relevant Cochrane review groups. Box 1 provides some tips for authors who want to copublish a Cochrane review, based on the Cochrane Community's editorial and publishing policy ${ }^{5}$ and our experience in editing this submission. In the meantime, the STICRG encourages clinicians and researchers to get involved in the STICRG. The STICRG editorial office is at the National University of Colombia, Bogotà, Colombia, and the group is a satellite of the Cochrane Gynaecology and Fertility Group. Look out for Cochrane Collaboration training courses
Box 1 Co-publication of a Cochrane review in Sexually Transmitted Infections

- Authors of a Cochrane review who want to publish an abridged version should read the Cochrane Community policy on co-publication.

- The BMJ Publishing Group has an agreement with the Cochrane Library to co-publish Cochrane reviews and authors need to complete a 'Permission to co-publish' form.

- An abridged Cochrane review will not be considered as a duplicate or redundant publication if it is consistent with the guidance from the International Committee of Medical Journal Editors regulations on secondary publication (http://www. icmje.org/icmje-recommendations. pdf), which includes clear citation and acknowledgement of the Cochrane review.

- The abridged version needs to be a stand-alone article. Readers need to be able to read and understand the abridged version without reference to the full Cochrane review. Authors should explain what they are reporting in the abridged version and what additional information can be found in the Cochrane review. All information about the included studies and the data used for the analysis need to be available in the abridged version.

- An abridged Cochrane review will undergo the full editorial process, including peer review, following submission to Sexually Transmitted Infections. Submission of an abridged Cochrane review does not guarantee acceptance.

- If invited to revise their manuscript, authors need to take into account peer reviewers' suggestions. If appropriate, the authors should take these changes into account when they update their Cochrane review.

- If changes to the manuscript result in differences in the results or the conclusions of the systematic review, the authors must discuss the changes with the Sexually Transmitted Infections Cochrane Review Group.

(https://training.cochrane.org/) online, webinars, workshops and long courses, and get in touch with our managing editor, Olga Gomez (cochranestiedito rialoffice@gmail.com),who can put you 
in touch with review authors. Help to make sure that the management of STIs is based on the best possible evidence.

Handling editor Jackie A Cassell

Funding The author has not declared a specific grant for this research from any funding agency in the public, commercial or not-for-profit sectors.

Competing interests $\mathrm{NL}$ is a member of the editorial board of the Sexually Transmitted Infections Cochrane Review Group and a deputy editor of Sexually Transmitted Infections.

Provenance and peer review Commissioned; internally peer reviewed.

(c) Author(s) (or their employer(s)) 2019. No commercial re-use. See rights and permissions. Published by BMJ.

\section{Check for updates}

To cite Low N. Sex Transm Infect 2019;95:2-3.

Received 14 September 2018

Accepted 25 September 2018

Published Online First 19 October 2018

\section{(S) Linked}

http://dx.doi.org/10.1136/sextrans-2018-053693

Sex Transm Infect 2019:95:2-3.

doi:10.1136/sextrans-2018-053762

\section{REFERENCES}

1 Savaris RF, Fuhrich DG, Duarte RV. Antibiotic therapy for pelvic inflammatory disease: an abridged version of a Cochrane systematic review and meta-analysis of randomised controlled trials. Sex Transm Infect 2019:95:21-7.

2 Gaitan-Duarte HG, Farquhar C, Horvath T, et al. The sexually transmitted infections and HIV/AIDS Cochrane review groups. Sex Transm Infect 2014;90:259-60.

3 Ness RB, Hillier SL, Kip KE, et al. Bacterial vaginosis and risk of pelvic inflammatory disease. Obstet Gynecol 2004:104:761-9.

4 Guideline Development Group. UK national guideline for the management of pelvic inflammatory disease 2018. Available from: https://www.bashh.org/guidelines

5 Cochrane Editorial Unit, John Wiley \& Sons Ltd. Editorial and Publishing Policy Resource. Co-publication 2011. Available from: https://community.cochrane.org/ editorial-and-publishing-policy-resource/co-publication 